service. It is for doctors and nurses therefore to forestall such pressures by ensuring that sympathetic attention as well as first-class medical care is available to all mothers in hospital.

The family doctor who is skilled in obstetrics will ask what part he is to play with an increasing number of deliveries taking place in hospital. He will of course continue to be responsible for any domiciliary confinements, though the report recommends that all women should be seen at least twice by a consultant during the antenatal period. The report also sees him as an essential member of the district hospital divisional obstetric team linking up with the consultant obstetrician and the midwife. But a viable future is not seen for small isolated cbstetric units, which, it is argued, should be replaced by combined consultant and general practitioner units in district hospitals with medical and nursing staff effecting close liaison with group practices and health centres in the area. This is reasonable, but an efficient transport system must be laid on for those patients living in rural areas. Indeed, in remote areas there may always be a place for domiciliary midwifery.

In advocating the development of the hospital-based obstetric team the report proposes that local authorities should withdraw altcgether from obstetric care, with general practitioners taking over the work previously done in their antenatal and postnatal clinics. With most mothers in hospital for only a short time after delivery general practitioners will also be responsible for the postnatal supervision of such patients. So there will still be an active role both in and outside the hospital for suitably qualified family doctors interested in practising obstetrics.

\section{Results of Vagotomy}

It is some 25 years since Lester Dragstedt ${ }^{1}$ introduced vagotomy with gastric drainage as a rival to subtotal gastrectomy in the treatment of duodenal ulcer. From the abundant experience gained in that time it is now possible to attempt a dispassionate appraisal of the relative merits of these two operations. $^{2-5}$

Vagotomy and drainage by gastroenterostomy or pyloroplasty is followed by a higher recurrent ulcer rate than is subtotal gastrectomy ( 7 or $8 \%$ as against 1 or $2 \%$ ). As to the symptoms the patients experience after the two operations, there is little to choose between them, but dumping is more frequent and severe after the former, while diarrhoea is much commoner after the latter and in $2 \%$ of the cases is really troublesome. Anaemia and persistent loss of weight are usually less frequent after vagotomy and drainage than after gastrectomy.

It is when one compares the immediate risks that vagotomy and drainage shows to best advantage. When subtotal gastrectomy was the routine surgical treatment for duodenal ulcer, the operative mortality, though occasionally as low as $1 \%$ in exceptionally experienced hands, was usually nearer 3 or $4 \%$, being specially high in patients undergoing emergency resections for penetrating posterior-wall ulcers causing bleeding. ${ }^{6-11}$ By contrast, many reported series of patients with duodenal ulcer treated by elective vagotomy with gastroenterostomy or pyloroplasty have had immediate mortality rates of under $1 \% \cdot{ }^{12-14}$ The greater safety of this procedure emerges most strikingly in dealing with bleeding ulcers, for which vagotomy and pyloroplasty, with under-
Difficulty has arisen in short-stay hospital confinements over the care of mothers when they return home. Some district midwives are understandably unenthusiastic about dealing with the less interesting phase of childbirth. The establishment of a unified midwifery service based on district hospitals with midwives going out into the community should $\stackrel{\mathbb{Q}}{\circ}$

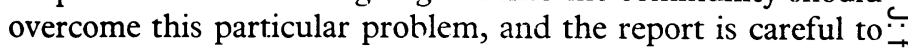
indicate the scope and freedom the committee envisages for $\overrightarrow{\vec{F}}$ midwives.

Nevertheless, nurses who have chosen to do midwifery on the district may not be inclined to move into hospitals, $\frac{\pi}{\sigma}$ especially large district hospitals, many of which are already short of trained obstetric staff. The dangers of insufficient क staff trying to cope with the ccmbined load of community as $\overrightarrow{0}$ well as hospital care must be anticipated, otherwise recruitment $\overrightarrow{-}$ is likely to be affected adversely and the high standards of ${ }_{\sigma}^{\omega}$ nursing care in obstetric units to be endangered.

This report from Sir John Peel and his colleagues has $\frac{3}{\omega}$ obviously been based on carefully evaluated evidence. It is to of be welcomed for offering a constructive programme for $\vec{\oplus}$ developing obstetric care and also because it sees family planning as an integral part of obstetrics. The warnings from $\infty$ human ecologists about the ill effects of overpopulation must $\frac{\text { ? }}{5}$ be taken seriously, and the medical profession cannot regard $\vec{G}$ its responsibilities in obstetrics as properly discharged unless $D$ doctors are prepared to advise mothers on birth control ate a time when it can be discussed most naturally.

Domiciliary Midwifery and Maternity Bed Needs, Report of the Subcommittee of the Standing Maternity and Midwifery Advisory Com-. mittee of the Central Health Services Council. London, H.M.S.O., 1970.

running of the bleeding point in the floor of the ulcer through $\frac{\vec{\circ}}{3}$ the pyloroplasty wound, has proved to be a much less hazardous manoeuvre than gastric resection and nearly as effective in controlling the haemorrhage. ${ }^{15} 16$ Probably the main attraction of vagotomy and a drainage operation for the average surgeon is its lower mortality, for though recurrent ulcers are a drawback they can often be cured by a further operation, but $\frac{3}{6}$. an operative death is an irretrievable tragedy. Certainly it is no $\frac{\delta}{2}$ longer justifiable to submit to partial gastrectomy any patient with duodenal ulcer in whom special difficulties in the conduct of the operation are to be apprehended now that the $\mathcal{N}$ safer alternative of vagotomy and drainage is available.

What can be done to improve the results of vagotomy? Recurrent ulcer after this operation is a complication not of $\mathcal{N}^{-}$ vagotomy but essentially of incomplete vagotomy, and the best preventive of recurrence is complete vagal-nerve section. Unfortunately most surgeons have an incomplete-vagotomy rate on Hollander insulin testing of around $20 \% \cdot{ }^{17} \stackrel{\mathbb{\infty}}{\rightarrow}$ This week in the B.M.F. (p.372) Mr. H. Burge and colleagues, going on from earlier reports on the use of his vagal-nerveo stimulator, ${ }^{18} 19$ analyse the causes of failure to obtain complete vagotomy in 9 cases. Another approach to the $\underset{\mathbb{Q}}{\mathbb{Q}}$ prevention of recurrent ulcer after vagotomy is to combine this operation not with a simple drainage procedure but with $\delta$ an antrectomy, or distal one-third or one-half gastrectomy, to을 reduce more effectively the gastric secretion mediated by the gastrin mechanism. This combination is certainly excellent, $\rightleftharpoons$ in avoiding recurrence, but it involves the same technical difficulties and dangers as an ordinary subtotal gastrectomy. ${ }^{20-22}$

"Selective" vagotomy, in which the vagal branches to the 
biliary apparatus and coeliac plexus are conserved, has been advocated as a means of avoiding post-vagotomy diarrhoea, ${ }^{19}$ and a recent controlled trial by T. Kennedy and A. $M$. Connell ${ }^{23}{ }^{24}$ has shown a significantly lower incidence of diarrhoea when the selective technique was used. Unfortunately many surgeons are likely to be deterred by the greater technical difficulty of the selective operation. A recent interesting innovation has been the use of "selective" and "highly selective" vagotomy respectively without a drainage operation, ${ }^{25} 26$ in the hope of avoiding dumping and other disturbances of gastrointestinal function. Originally Dragstedt ${ }^{1}$ had tried ordinary vagotomy alone and been compelled by the frequent occurrence of vomiting and belching to change to vagotomy with drainage. So far Burge ${ }^{25}$ and D. Johnston and A. R. Wilkinson ${ }^{26}$ have had encouraging results with little or no trouble from gastric retention, but a more extensive trial will be needed to evaluate these methods.

The foregoing remarks apply exclusively to the treatment of duodenal ulcer. But vagotomy has been championed for gastric ulcer as well by some authors, as Mr. H. Burge and his colleagues do for some types of cases in their article at page 376 of this issue of the B.M.F., though the rationale for its use in this condition may be questioned. H. L. Duthie ${ }^{27}{ }^{28}$ compared the results of vagotomy and pyloroplasty with those of Billroth 1 resection in a controlled trial on patients with gastric ulcers unaccompanied by any duodenal lesions. There were no operative deaths after either operation, and on a 6-months to 3-years follow-up the functional results were distinctly better in the gastrectomy group. Moreover, the incidence of recurrent ulcer was only $2.4 \%$ after gastrectomy, but $14.3 \%$ after vagotomy and pyloroplasty-a difference that just fails to be statistically significant. An important point that arises too is the risk of carcinoma of the stomach being mistaken for a benign gastric ulcer till histological examination is performed-an error that occurred in 6 of 92 cases in Duthie's experience ${ }^{28}$ and in 11 of 88 cases reviewed by G. S. Sokhi. ${ }^{29}$

In the light of these findings most surgeons will probably

1 Dragstedt, L. R., Annals of Surgery, 1945, 122, 973.

2 Goligher, J. C., $t$ t al., British Medical fournal, 1968a, 2, 781.

3 Goligher, J. C., et al., British Medical fournal, 1968b, 2, 787.

4 Cox, A. G., British Medical fournal, 1968, 1, 288. Pulvertaft, C. N., and Cox, A. G., in After Vagotomy,

Hosford, J., British Medical fournal, 1949, 1, 929.

7 McKeown, K. C., British fournal of Surgery, 1962, 50, 131

Priestley, J. T., Walters, W., Gray, H. K., Waugh, J. M., and Judd, E. S. Proceedings of the Staff Meetings of the Mayo Clinic, 1954, 31, 62.

- Harvey, H. D., Surgery, Gynecology and Obstetrics, 1961, 112, 203.

10 Goligher, J. C., and Riley, T. R., Lancet, 1952, 1, 630.

1 Amdrup, E., Andreassen, J. C., and Bach-Nielsen, P., Acta Chirurgica Scandinavica Suppl., No. 396, 1969, 18.

12 Holt, R. L., and Robinson, A. F., British fournal of Surgery, 1955, 42, 494.

13 Hindmarsh, F. D., Lancet, 1957, 1, 1113 .

14 Weinberg, J. A., Stempien, S. J., Movius, H. J., and Dagradi, A. E., American Fournal of Surgery, 1956, 92, 202.

15 Dorton, H. E., Annals of Surgery, 1961, 153, 378.

16 Carruthers, R. K., Giles, G. R., Clark, C. G., and Goligher, J. C., British Medical fournal, 1967, 1, 80.

17 Fawcett, A. N., Johnston, D., and Duthie, H. L., British fournal of Surgery, 1969, 56, 111.

18 Burge, H., and Vane, J. R., British Medical fournal, 1958, 1, 615.

12 Burge, H., in Vagotomy. London, Arnold, 1964 . Archives of Surgery, 1960, 80, 743.

2 Palumbo, L. T., Sharpe, S., Lulu, D. J., Bloom, M. H., and Porter, H. R., Surgery, 1962, 51, 289.

22 Edwards, L. W., et al., American fournal of Surgery, 1963, 105, 352

23 Kennedy, T., and Connell, A. M., Lancet, 1969, 1, 899.

24 Kennedy, T, and Connell, A. M., Lancet, 1969, 1, 675.

25 Burge, H., MacLean, C., Stedeford, R., Pinn, G., and Hollander, D., British Medical fournal, 1969, 3, 690.

26 Johnston, D., and Wilkinson, A. R., British fournal of Surgery, 1970, 57, 289.

27 Duthie, H. L., and Smith, G. H., Fournal of the Royal College of Surgeons of Edinburgh, 1968, 13, 324

1 Duthie, H. L., Gut, 1970, 11, 540.

20 Sokhi, G. S., Fournal of the Royal College of Surgeons of Edinburgh, 1970, 15,108 . prefer to restrict their use of vagotomy with pyloroplasty for the treatment of gastric ulcer to those patients with associated duodenal lesions or with ulcers high on the lesser curve, where a resection might be difficult or very extensive. And it is clearly desirable to remove as much as possible of the ulcer edge through a gastrotomy for frozen-section examination to exclude carcinoma and avoid the performance of a futile, conservative operation for a malignant condition.

\section{Government's Decision}

In deciding for compelling economic reasons to knock a third off the Review Body's recommendations, as they apply to senior hospital doctors' and general practitioners' pay, the Government has acted within the rules. But the doctors' acceptance of the decision will nevertheless be grudging. The blow is a little softened by the fact that the position is to be reviewed next April-instead of in April 1972, as recommended by the Review Body-and by Sir Keith Joseph's blunt words, in his letter printed in the Supplement, about the threat of inflation to Britain's economy. However, medical men and women would be more prepared for sacrifice if they could be really convinced it would be in the national interest, and if the altar did not seem to them so much like a burning deck whence all but they had fled.

A graver matter would be if recent events turned out to have done grievous injury to the review body system for settling doctors' and dentists' pay. This was supposed, among other things, to take decisions on these matters away from influences of political expediency. Yet the previous Government's decision to pay the Review Body's overall award of $30 \%$ in full to junior doctors and not to others was blatantly political and expedient. The imbalance it has caused in relativities in medical remuneration will continue to cause trouble for a long time, and it will certainly need some further intervention by the present Government to correct, in particular, the anomalies created in the pay of junior consultants. It is to be hoped that the additional money for adjusting these anomalies, referred to in paragraph (6) of Sir Keith Joseph's letter, will be forthcoming in generous amounts. An even distribution of specialist care throughout the provinces has been perhaps the most beneficial outcome of the N.H.S., and it may well now be lost if something is not done quickly for provincial consultants.

Apart from settling details of remuneration, there is much urgent work to be done towards setting up a new review body. Perhaps the most important part of this will be for the medical profession to insist that the new body will be better and more quickly supplied with essential information than was Lord Kindersley's committee. This is a matter in which the Health Departments and the professions should co-operate more than they have done. The Review Body has been in fact if not in name an arbitration tribunal, and each side has approached it in the mood to make and win a case. This may be almost inevitable, but surely fairer and therefore less disputatious results might be obtained if both sides first looked for common ground and agreed to produce relevant information to support it. It is most unjust that over several years doctors should have received less than their due because essential information had not been available to the Review Body, and that when, in its Twelfth Report, the Review Body sought to remedy the injustice its award should have been rejected because it was inflationary. There is much food for thought in paragraph (4) of Sir Keith Joseph's letter. 